\title{
A produção de conhecimento acerca da pessoa surda na área da Educação Física
}

\author{
The production of knowledge about the deaf person \\ in the field of Physical Education
}

\author{
Vinícius Fin', Eduardo Klein Carmona', Janice Zarpellon Mazo \\ 'Universidade Federal do Rio Grande do Sul (UFRGS), Porto Alegre, RS, Brasil.
}

Recebido em: novembro 2015 / Aceito em: novembro 2015

eduardok.carmona@hotmail.com

\section{RESUMO}

Os profissionais de Educação Física, nos dias de hoje, atuam em diversos espaços além da escola e do clube, atingindo diferentes grupos sociais. No que diz respeito ao aluno surdo, em especial, percebe-se uma grande dificuldade quanto à comunicação, visto que em muitas situações não é possível o contato visual entre o aluno e o professor. Além disso, percebe-se que a maioria dos professores não é fluente na Língua Brasileira de Sinais (LIBRAS). O objetivo da pesquisa é realizar uma revisão bibliográfica sobre a produção do conhecimento acerca da pessoa surda, no campo da Educação Física. Identificou-se que as temáticas recorrentes nas publicações foram atividades rítmicas e comunicação entre o aluno surdo e o professor/colega. Outros assuntos foram contemplados nos trabalhos acadêmicos analisados, contudo evidenciou-se uma carência de publicações na área da Educação Física sobre a pessoa surda.

Palavras-chave: Surdo; Língua Brasileira de Sinais - LIBRAS; Educação Física.

\section{ABSTRACT}

Nowadays the Physical Education professionals act in many distinct environments beyond school and club, reaching different social groups. Regarding the deaf students, particularly, we realize great difficulty when it comes to communication, since in many situations eye contact between student and teacher is not possible. In addition, it is clear that most teachers aren't fluent in our national sign language (Língua Brasileira de Sinais, also known as LIBRAS). The objective of the research is to perform a literature review about the knowledge production around the deaf person, specifically on Physical Education area. At the end of the work, we found that the most common subjects in the academic production were on rhythmic activities and communication between the deaf student and teacher/colleague. Other issues were found among the academic papers analyzed, however the whole research evidenced a lack of publications about the deaf person in Physical Education area.

Keywords: Deaf; Brazilian Sign Language - LIBRAS; Physical Education.

\section{INTRODUCÃ̃}

A surdez é a perda da habilidade de ouvir, sem designação do grau ou da causa; surdo é alguém para quem o sentido da audição não é funcional, com ou sem amplificação, para os propósitos comuns da vida. ${ }^{1} \mathrm{~A}$ surdez caracteriza-se por uma diminuição na acuidade auditiva que faz com que a audição pura e simples que seja suficiente para a compreensão, com ou sem o uso de ajuda auditiva (aparelho de surdez e/ou implante coclear, por exemplo). Pode-se definir o termo anacusia como perda total da audição, enquanto hipoacusia significa uma redução na capacidade da percepção auditiva. ${ }^{2}$

Já a deficiência auditiva caracteriza-se pela diminuição da percepção dos sons, evidenciando um mau funcionamento do mecanismo auditivo. Portanto, a deficiência pode existir sem que haja surdez. Além disso, a perda auditiva é tão severa que impossibilita o processamento da linguagem através da audição, utilizando outras formas de comunicação. Enquanto que, os deficientes auditivos utilizam o aparelho de surdez e/ou 
a ajuda terapêutica na comunicação.

A pessoa com surdez é vista, em geral, como um ser inferior e até anormal em alguns casos, além de dependente de outras pessoas. ${ }^{3}$ A ciência moderna instituiu o paradigma biomédico como discurso hegemônico para a surdez e o surdo no domínio da saúde. Com isso, a surdez passou a ser vista pelo ponto de vista orgânico-biológico, sendo classificado em diferentes graus de incapacidade de audição. ${ }^{4}$ Neste contexto, pessoas com surdez passaram a ser denominadas deficientes auditivas e a serem tratadas em sua integralidade humana, como deficientes.

A história social da surdez mostra o quanto os surdos vêm sendo alvo de controle dos médicos, principalmente por desafiarem os limites normativos do normal e do patológico. Esta concepção, ancorada na perspectiva do déficit, afirma que a surdez é uma deficiência auditiva, conferindo à tecnologia um método para adaptá-lo e normatizá-lo à sociedade ouvinte. Em contrapartida, o surdo percebe a surdez como identidade, lutando por reconhecimento, e não por adaptação. ${ }^{4}$ Essa identidade, aliada a sua própria cultura e à língua de sinais, constituem uma unidade definidora da surdez, na qual o "ser surdo" passa a ser uma questão antes de identidade do que biológica.

Entretanto, assumir a identidade surda ainda é um processo complexo para muitos surdos, já que isso significaria assumir a própria condição de surdez e fazer parte de um grupo minoritário, muito discriminado atualmente. Portanto, a surdez não é homogênea, ou seja, o grupo de surdos não é uniforme, há mulheres surdas, surdos negros, entre outros, os quais constituem múltiplas identidades surdas. De acordo com Klein e Lunardi, ${ }^{5}$ não podemos centrar as culturas surdas pelo uso da língua de sinais como única expressão autêntica dessa cultura, de modo a não cristalizar a surdez a partir de um "único" recorte cultural, para que ela não se torne mais uma forma "exótica" e "folclórica" de entendimento da surdez.

Assim, percebemos que a discussão sobre identidade surda não está desvinculada da cultura surda, pois, na medida em que os surdos legitimam sua língua e sua comunidade, temos o crescimento dessa cultura (humor, arte, poesia, etc.). Esta pode ser entendida como a coordenação entre um conjunto de normas e práticas dentro de uma sociedade. ${ }^{6}$ Os representantes da cultura surda defendem que estariam sendo julgados anormais pelo simples fato de não usarem a mesma língua que os ouvintes, ou seja, por não serem bilíngues (linguagem oral e LIBRAS), ou por não compartilharem dos valores culturais hegemônicos atuais. ${ }^{7}$ Skliar, ${ }^{8}$ por exemplo, trata especialmente da cultura dos surdos, entendida como a cultura de uma minoria linguística, bem representada em sua língua de sinais.

A Língua Brasileira de Sinais (LIBRAS) é a língua de sinais utilizada pela maioria dos surdos e reconhecida por lei. Não é uma simples forma de gestualização da Língua Portuguesa, mas uma língua a parte, visto que somente o conhecimento gestual não é suficiente para que a comunicação aconteça em sua plenitude. É denominada língua de modalidade gestual-visual (ou espaço visual), pois a informação linguística é recebida pelos olhos, e produzidas pelas mãos e rosto. De acordo com Gesueli ${ }^{9}$, a língua de sinais remete à identidade do sujeito que (con)vive, quase sempre, com as duas comunidades (surda e ouvinte). Dado o papel da linguagem como atividade constitutiva, é interessante perceber a relação língua e identidade, entendendo que o sujeito se constitui à medida que interage com os outros.

A comunidade surda, ou seja, as pessoas que possuem o sentimento de pertencimento à cultura surda, são definidas basicamente pela linguagem dos sinais, ao passo que surdos são todos os que não se identificam com o movimento social, ou porque foram pessoas socializadas em ambiente ouvinte ou porque têm variados graus de deficiência auditiva. ${ }^{7}$ Ao conhecerem outros surdos com as mesmas dificuldades - de escolarização e de comunicação -, com experiências comuns - o uso da prótese auditiva, conflito familiar e o preconceito e com os mesmos objetivos de vida, constitui-se uma condição identitária e cultural para a formação destas comunidades. Além disso, segundo Nóbrega et al., ${ }^{4}$ percebemos que a comunidade surda questiona a imposição tecnológica (para atenuar a deficiência auditiva), mesmo na infância, visto que a criança ainda não imergiu na cultura surda e não tem autonomia para escolher o que quer, a que grupo deseja pertencer. Eles defendem que a criança deveria crescer em um ambiente normal, conhecendo variados espaços de convivência, reconhecer cada um deles e os significando para que assim, depois de ter experimentado essas possibilidades, faça sua escolha. Ou seja, as comunidades surdas provocam a compreensão do modelo ético baseado na autonomia, visto que é realizada uma audiologia com as cirurgias de implante coclear, em que pais Surdos não autorizam que seus filhos submetam-se à cirurgia sob a alegação de que essa é uma forma de extermínio da cultura surda pela suposta cura da surdez. ${ }^{7}$

Em relação ao ambiente escolar, os problemas enfrentados pelas culturas de minorias, nesse caso os surdos, ficam mais claros, tendo em vista a convivência no ambiente cultural - escola - constituída pela homogeneização de atitudes e comportamentos subsidiários da cultura dominante (ouvinte). No entanto, de acordo com De Paula, ${ }^{6}$ a cultura escolar tem confrontado, cada vez mais, com a questão das diferenças culturais e isso tem trazido uma nova problematização: como lidar com essa questão. Contudo, pensar a escola a partir de uma perspectiva de uma mescla de culturas não se refere a um tranquilo processo de integração de diferenças, mas de um espaço com constantes ressignificações e discursos.

A Educação Física, enquanto disciplina escolar possui papel fundamental neste processo, visto que propicia diversas condições para estimular a inclusão do aluno surdo, principalmente com ações que promovam a motivação necessária para que ele se engaje nessas atividades. Assim como pode ser benéfica, também pode propiciar situações em que o surdo se exclua, ou seja, excluído das atividades, fazendo desse espaço um lugar de segregação e discriminação. Então, como há a mescla de várias culturas entre os próprios surdos, a cultura corporal de movimento, presente na Educação Física, por exemplo, não é algo estático, mas que se movimenta e torna o espaço propício para que os alunos possam expor suas opiniões, ideias e formas de se expressar, não só através da comunicação oral ou ges- 
tual, mas também corporalmente. Percebe-se, então, que a Educação Física e, consequentemente o esporte, compõem parte da cultura, tanto dos ouvintes quanto dos surdos, portanto se faz necessária uma pesquisa a respeito dessa faceta da cultura, especialmente a dos surdos ligados ao esporte, nesse caso.

Diante dessas considerações, o objetivo da pesquisa é realizar uma revisão bibliográfica sobre a produção do conhecimento acerca da pessoa surda, no campo da Educação Física, identificando as principais temáticas contempladas nas publicações analisadas.

A realização desse estudo justifica-se pela necessidade de diagnosticar a produção de conhecimento a respeito da relação do surdo e a Educação Física, pois identificou-se a escassez de produções científicas que tratem desta relação.

\section{METODOLOGIA}

Este é um estudo de revisão bibliográfica acerca do conhecimento no campo da Educação Física brasileira sobre o surdo, relacionando aspectos considerados fundamentais no processo de ensino-aprendizagem, discutindo sobre suas causas e consequências. Esta revisão está associada ao método de pesquisa bibliográfica, o qual consiste na pesquisa da bibliografia tornada pública, a respeito do assunto em questão, permitindo a exploração de novas áreas de estudo que possam emergir a partir da pesquisa. ${ }^{10}$ Para tanto, foram coletadas informações em bases de dados, mais especificamente, em periódicos da Educação Física e em anais de congressos da área, além de teses e dissertações de Programas de Pós-Graduação da área da Educação Física de universidades brasileiras.

Para a realização da busca por artigos em periódicos e em anais de congressos, foram utilizados os seguintes termos: surdo; surdez e; deficiência auditiva. A procura foi feita nos portais: Scielo; Pubmed e; Periódicos da CAPES. O critério utilizado para a seleção dos artigos foi conter os termos apresentados nas palavras-chave ou no título, além da leitura do resumo dos mesmos, de modo a confirmar que cada um tratava de assuntos do interesse desta. Foram encontrados oito artigos que correspondiam aos critérios adotados.

Para a realização da pesquisa por teses e dissertações, também foram utilizados os termos estabelecidos anteriormente: surdo; surdez e; deficiência auditiva. A procura foi feita diretamente nos repositórios digitais das seguintes Universidades: UFRGS; UNICAMP; UFPel; UFPR; USP; UFSM; UDESC; UFSC; UEM/UEL. Estas Universidades foram escolhidas por possuírem programas de pós-graduação strito sensu na área específica a ser analisada. Ao todo, foram encontradas quatro teses/dissertações.

As informações coletadas foram submetidas à análise de conteúdo e, os resultados obtidos foram distribuídos em tópicos, a fim de que fossem estabelecidas intersecções e aprofundamentos entre as informações encontradas durante a pesquisa. Os focos da análise da pesquisa bibliográfica trataram de questões recorrentes na maioria dos trabalhos investigativos analisados, além de serem destacadas temáticas de estudo importantes tanto para o desenvolvimento da aula com esse público, bem como seu desenvolvimento a partir dessas experiências. Os resultados da análise são apresentados em dois tópicos: a) Ritmo e dança, abordados como potenciais métodos para a melhoria da comunicação e aprendizagem do aluno surdo; b) Comunicação entre o ouvinte e a pessoa surda, o qual trata de um diagnóstico sobre as formas de comunicação utilizadas pela pessoa surda, tanto no ambiente escolar, quanto fora dele.

\section{Ritmo e Dança}

Por meio da leitura e análise dos trabalhos encontrados, foi possível perceber que a temática do ritmo associado à dança é uma das manifestações mais recorrentes. Isso demonstra que o fato de os surdos não serem capazes de ouvir, não significa que os mesmos não são capazes de "sentir" a música e suas vibrações, além de compreender o ritmo através de outras ferramentas, não somente com a utilização da música.

A dança pode expressar uma ideia de forma não verbal "com o objetivo de atingir a sociedade como um grito de liberdade", seja individualmente, ou coletivamente. ${ }^{11}$ Os surdos, ainda que isolados do mundo sonoro, têm suficiente capacidade para integrar-se ao movimento e dança. ${ }^{12}$ De acordo com o autor, por meio da integração dos mesmos às classes de ouvintes, estes se sentem invadidos pelo ritmo coletivo, aprendendo a reconhecê-lo e expressá-lo através da dança, transformando a dança em linguagem de comunicação que o permita sair de seu isolamento. Podemos perceber que a dança é um possível meio de comunicação com o mundo externo, no qual o surdo é capaz de se expressar e, mais do que isso, se reconhecer como indivíduo pertencente à sociedade, talvez não de modo igualitário em relação aos ouvintes, mas com as mesmas condições e possibilidades de expor seus sentimentos. Os movimentos da dança ordenados em tempo e espaço se tornam, durante a dança, uma válvula de escape, de uma vida cheia de conflitos. Por vezes, isto acaba se tornando uma forma de expressar seus desejos, pesares, respeito e temores. ${ }^{11}$

O movimento corporal se configura como linguagem, uma maneira de manifestar-se que pode ser resgatado em detalhes através da expressão corporal, desenvolvendo assim as potencialidades. ${ }^{11} \mathrm{O}$ que acontece é que muitas pessoas não acreditam que os surdos podem dançar justamente por pensarem que a música pode ser apenas ouvida, e ignoram a ideia de que ela pode ser sentida. Na maioria dos casos, isto ocorre devido à falta de informação da população a respeito do indivíduo surdo, principalmente a questão da compensação dos sentidos, evidenciada nesse caso, já que os surdos possuem o sentido de tato muito aguçado e acabam sentindo a música através do vibrato, seja nos objetos ao seu redor, nas paredes ou até mesmo na própria roupa. Isso faz com que eles conheçam o ritmo da música mesmo sem ouvir nada, ou melhor, eles ouvem com o seu corpo não apenas com os ouvidos. ${ }^{11}$ Lopes e Araújo ${ }^{12}$ mencionam que a criança traz em si a pulsação natural do coração; na respiração, a divisão de tempo e; nos movimentos, o ritmo. É fundamental que o surdo identifique o próprio ritmo dentro das mais diversas atividades e movimentos do dia a dia, o que viria a facilitar a aprendizagem da dança, além do entendimento do mesmo a respeito de suas particularidades como ser humano. 
De acordo com Luiz, ${ }^{13}$ o surdo possui, como todas as pessoas, um ritmo que lhe é próprio, e que a utilização das estruturas utilizadas (coelhos e tartarugas) no estudo contribuiu também na compreensão deste ritmo próprio que para muitos era imperceptível. Esta questão se torna importante, pois a aquisição do senso rítmico traz benefícios também em termos da aquisição de padrões de movimentos mais coordenados; no estabelecimento do equilíbrio e desenvoltura na expressão corporal. Isto é confirmado por Lopes e Araújo, ${ }^{12}$ no qual se constatou que as crianças apresentaram melhora no equilíbrio, desenvolvimento psicomotor, rítmico, afetivo e social após ter sido aplicada a sequência de aulas de sapateado. O ritmo, marcado pelas suas várias formas, ao som ou não da música, seria o ponto de partida para que a atividade corporal desenvolvida no espaço e no tempo determinado e configurado pelo ritmo transformasse na expressão dança os movimentos comuns do ser humano. ${ }^{13}$ Cabe ressaltar a importância de um padrão de ritmo próprio, o que facilita as ações do cotidiano, pois caso a pessoa surda não consiga reconhecê-lo em seu corpo, provavelmente ela fará isso por imitação, o que pode causar ações descontextualizadas.

A dança, para os surdos, se torna muito importante, pois constituísse em um instrumento que torna possível o autoreconhecimento da sua corporeidade, através do desenvolvimento: da linguagem quando os faz se expressar através de movimentos, característica de extrema importância para eles; do entendimento sobre diversidade entendendo assim que todos possuem necessidades diferentes; da cognição se tornando um ser pensante em todos os aspectos da vida; e da sua criatividade se tornando mais livres no seu processo de criação. ${ }^{11} \mathrm{O}$ universo dos surdos é, genericamente, limitado em função da quantidade de experiências diversificadas que o surdo deixa de adquirir ao longo de sua vida, em função desta limitação, alguns aspectos corporais são comprometidos, e o surdo tem dificuldade em relaxar, canalizar a energia contida, conter a ansiedade. ${ }^{13}$ Através destas experiências rítmicas, o surdo é capaz de perceber suas possibilidades e potencialidades, não só em relação a sua expressividade, na utilização do corpo como linguagem, mas também a oportunidade de desfrutar de uma atividade integradora, firmando amizades e estabelecendo convívio com os demais. Luiz ${ }^{13}$ afirma existir certa preocupação com o isolamento deste público, utilizando a música para colocá-las em comunicação com o ambiente e tirá-las do seu mundo fechado e incompreendido de ser.

$\mathrm{Na}$ dança moderna, por ser considerada uma modalidade livre, o professor não impõe ao aluno sequências externas prontas, mas torna-se guia e os orienta para uma descoberta pessoal de suas possibilidades. ${ }^{13}$ Devido a essa liberdade, cada aluno motiva-se a buscar dentro de si próprio a fonte inspiradora de sua movimentação, na qual essa fonte inspiradora pode imergir das mais variadas sensações, que só serão possíveis caso o indivíduo se permita a tê-las ou tenha a oportunidade de vivenciá-las. Entretanto, para Bregolato citado por Luiz, $^{13}$ os alunos que estiverem muito condicionados e oprimidos vão resistir a ela, e preferir a apatia e o conformismo em apenas copiar os modelos estabelecidos. Portanto, é imprescindível uma preocupação especial com o desenvolvimento dessas atividades, o processo de ensino-aprendizagem que está sendo desenvolvida a dança e suas ramificações. É mais valioso o próprio processo de desenvolvimento que o eventual resultado que se obtenha, ou seja, todo o processo de aquisição, no qual o indivíduo passa por dificuldades, conflitos e temores, se torna parte fundamental e constituinte deste indivíduo, no qual suas experiências tornam-se mais ricas do que o próprio conhecimento. ${ }^{13}$

De acordo com Alves, Santos e Carvalho, ${ }^{11}$ a dança pode proporcionar aos surdos um entendimento maior da sua diferença, e melhor, que a aceitem, entendendo que apesar de serem surdos eles podem realizar atividade que se acreditava apenas possível para os que ouvem. Contudo, essa dita "diferença" também pode ser percebida quando relacionamos a pessoa surda a outro grupo social, nesse caso, em situação oposta. Muitas vezes, a sociedade trata o surdo como indivíduo incapaz de realizar a maioria das atividades diárias sem algum tipo de ajuda, designando-o como dependente. Luiz ${ }^{13}$ apontou uma situação na qual o surdo incorporou o papel do ouvinte, observando indivíduos que possuíam paralisia cerebral participarem de suas aulas, os estigmatizando como inferiores. Entretanto, com o convívio, percebeu-se uma mudança de atitude do grupo frente esses colegas, no qual, por vezes, os alunos com paralisia cerebral lembravam-se de movimentos mais rapidamente do que os surdos. Por viverem constantemente situações deselegantes como esta, é difícil pensar que eles poderiam reproduzir esse sentimento de inferiorização em relação a outro grupo social, provavelmente devido ao fato da mera reprodução de estereótipos da sociedade atual.

O processo de aprendizagem através da dança, pelos surdos, está ligado justamente à aceitação da sua condição, obtendo assim o conhecimento de seus limites e possibilidades, ${ }^{11}$ bem como o entendimento das potencialidades de outros indivíduos, que eles mesmos consideram como incapazes. Foi confirmado, segundo Lopes e Araújo, ${ }^{12}$ que o sapateado é uma das formas viáveis e pode ser incentivado para a criança surda, assim como a dança e seus padrões rítmicos ${ }^{11,13}$ desde que seja trabalhado por profissionais que conheçam esta modalidade de dança e que possuam conhecimento básico de LIBRAS.

\section{Comunicação entre o ouvinte e a pessoa surda}

Através da leitura dos trabalhos encontrados foi possível perceber que o tema da comunicação, para a pessoa surda, é um fator indispensável a ser observado, quando falamos em aprendizagem na escola e, até mesmo, fora dela. Este subcapítulo apresentará a análise deste tema, envolvendo não só o aluno e o professor, mas também o aluno com seu colega, seja ele ouvinte ou não. É fundamental este entendimento, pois o surdo possui grandes dificuldades de se comunicar com os ouvintes, principalmente devido ao déficit na oralização.

O maior problema que o surdo já enfrentou foi, e continua sendo, a comunicação com a sociedade. A maioria dos surdos faz parte de uma cultura separada, porque a comunicação com as pessoas ouvintes é normalmente difícil; a comunicação normal (do ponto de vista dos surdos) é fácil quando eles estão juntos. ${ }^{13}$ Em relação às crianças, em estudo de Rossi, ${ }^{14}$ foi 
possível perceber que as trocas comunicativas seriam ideais caso ocorressem sempre dentro de um contexto significativo para a criança, do qual ela se sinta parte integrante e possa intercambiar os papéis de locutor e de interlocutor, nesse acaso, através da brincadeira entre mãe e filho. Isto nos demonstra a importância de uma comunicação adequada desde cedo, na qual a criança passa a expressar suas vontades e desejos em ambientes propícios a ela, onde a criança não se sinta intimidada, mas sim, relaxada. De acordo com Pasetto, ${ }^{15}$ é preciso tomar cuidado também com a "atenção dividida", já que a criança surda não consegue perceber o que o pai ou a mãe está falando e, ao mesmo tempo, visualizar o objeto do qual estão se referindo, é necessária uma explicação pausada e, falando sobre uma coisa de cada vez. Conforme Luiz, ${ }^{13}$ a criança surda começa a se comunicar por sinais antes que uma criança ouvinte consiga começar a falar. Além disso, a criança ouvinte também começa a se comunicar através de gestos antes de começar a falar, talvez não em LIBRAS, por não ser necessário, mas apontando para objetos, para comidas ou bebidas que deseja, além de utilizar de expressões faciais, por vezes não de modo voluntário, mas facilitando a comunicação com seu responsável. Em relação à comunicação fora do ambiente familiar, Rossi $^{14}$ afirma que os pais possuem papel importante, visto que assumem as consequências da surdez e utilizam com seu filho surdo, todo tipo de recurso comunicativo, favorecendo sua "autonomia pessoal".

De acordo com Venditti Júnior e Araújo, ${ }^{16}$ a aprendizagem da LIBRAS, por parte dos professores, permite a capacitação para lidar, comunicar e trabalhar com este público. De acordo com Gonçalves, Vaz e Fernandes, ${ }^{17}$ o contato entre criança e professor, por meio de LIBRAS, acontecia quase que exclusivamente com o professor, de forma que, provavelmente, ela acabava por identificar essa linguagem como particular e circunscrita a esta relação, não tendo se reconhecido ainda como parte integrante da comunidade surda. Isso nos remete a questão de a criança estar permeada por um mundo desconhecido, onde ela precisa se ambientar e se adequar, visto que o contrário dificilmente ocorre, principalmente na escola.

No ambiente escolar, normalmente não são proporcionadas condições efetivas de comunicação, já que grande parte dos professores não possui formação adequada para isso, o que é confirmado por Gonçalves, Vaz e Fernandes. ${ }^{17}$ De acordo com Barcelos, Porto e Geller, ${ }^{18}$ muitos profissionais da Educação Física ainda possuem receio e insegurança, devido à falta de preparação, o que estabeleceria um processo de comunicação e de trabalho apropriado com os surdos. Na investigação de Gonçalves, Vaz e Fernandes, ${ }^{17}$ ainda podemos constatar que a oralização da pessoa surda era muitas vezes incompreensível, e quando percebia que sua mensagem não fora entendida, demonstrava nervosismo e ansiedade, prejudicando a comunicação entre ambos.

A não compreensão por parte do professor das necessidades do aluno surdo pode prejudicá-lo em seu desenvolvimento, dificultando o bom desenvolvimento do aluno. ${ }^{19}$ Isto também pode ser observado em estudo realizado por Nazareth, ${ }^{20}$ na qual o tempo empreendido para ensinar os fundamentos técnicos da esgrima a alu- nos surdos foi maior em relação ao que normalmente é utilizado com alunos ouvintes, o que pode ocorrer devido ao fato da dificuldade de comunicação entre o professor e o aluno. Contudo, a aprendizagem dos fundamentos técnicos foi dificultada por causa da comunicação faIha, pois seriam coisas que não fariam sentido para o indivíduo, não haveria formas de explicação a não ser de modo oral, ou escrito, o que viria a problematizar a aplicação prática do conteúdo a ser aprendido. Nesse sentido, Pasetto ${ }^{15}$ nos traz a possibilidade da utilização da dica cinestésica, a qual auxiliaria na explicação de alguns movimentos e percepções do corpo por parte do indivíduo, não fazendo com que a tarefa se torne tão abstrata.

É imperativo tratar de outro fator que influencia diretamente no desenvolvimento global do aluno e está totalmente relacionado com a questão da comunicação: a prática do bullying. Barbosa ${ }^{3}$ relata que casos de bullying são mais evidentes nas aulas de Educação Física devido aos atos de agressividade e competitividade que a disciplina pode vir a proporcionar. É importante que o profissional de Educação Física tenha capacidade para distinguir e diagnosticar estas práticas no âmbito da escola, bem como proporcionar estratégias para que novos casos não surjam. Entretanto, caso isto não ocorra, o aluno pode sentir-se vítima destas ações e não sentir confiança no professor, fazendo com que ele não peça ajuda quando necessita. ${ }^{3}$

O caminho inverso pode ser percebido quando, em investigação realizada por $\mathrm{Luiz}^{13}$ indivíduos com paralisia cerebral participaram concomitantemente da pesquisa e, os alunos surdos, os viam como incapazes de tomar decisões e decidir frente ao grupo, ocorrendo uma das manifestações do bullying, privando o indivíduo de participar de algum grupo social, estabelecendo um estereótipo de inferioridade, algo que diminuiu com o decorrer da pesquisa.

Com estas situações, podemos prever que o estereótipo em vigor atualmente, considera um ou outro, frágil, incapaz, incompleto em algum sentido, seja ele por alguma deficiência ou outros problemas que permeiam o ambiente social. É necessário que o professor seja capaz de incluir o aluno na aula de um modo que não o faça parecer inferior, diminuindo o nível do exercício por causa do mesmo, mas sim fazendo com que a pessoa surda contribua positiva e ativamente da construção do processo de ensino aprendizagem. Assim e, só assim, seus colegas serão capazes de perceber o real valor da inclusão, estabelecendo diferentes e adequadas formas de diálogo.

Quanto às diferentes formas de linguagem, Venditti Júnior e Araújo ${ }^{16}$ nos afirmam que a lógica dos sinais (LIBRAS), como forma de comunicação, além de muito eficiente, torna o trabalho muito próximo, fazendo com que ocorra uma troca de aprendizado facilitada. Entretanto, na investigação realizada por Gonçalves, Vaz e Fernandes, ${ }^{17}$ Alice (menina surda, foco do estudo de caso) parecia reconhecer sua condição de pessoa surda, porém rejeitava um elemento fundamental do contexto cultural dos surdos, a linguagem de sinais. Isto pode ter acontecido devido ao fato de a criança não estar acostumada a esse tipo de diálogo no ambiente escolar, causando certo estranhamento e, até desconforto para a garota. Remetendo a Nazareth, ${ }^{20}$ foi utilizada a abordagem de ensino que, prioritariamente, seguiu a 
abordagem de ensino da oralização, entretanto foram utilizados outros recursos, como modelos representativos, figuras e sinalizações não padronizadas, por exemplo.

Em trabalho realizado por Venditti Júnior e Araújo $^{16}$ demonstrou-se a preocupação com as formas de comunicação e transmissão das informações, na qual a informação deve ser transmitida corretamente, assimilada e compreendida, para que seja possível a tomada de eventuais providências e ações motoras tanto rápidas, quanto eficazes. Além disso, entre os próprios alunos, eles já não seguem apenas um sistema único de comunicação gestual, mas um mélange, ou seja, uma mistura de técnicas com alguns componentes da língua dos sinais, ${ }^{20}$ demonstrando não haver uma forma de comunicação única e global, mas sim um apanhado de várias técnicas que podem ser bem sucedidas, ou não.

Quando falamos em educação do aluno surdo, precisamos considerar todas as formas como são transmitidas as informações pertinentes, para que assim não haja falta de compreensão da tarefa. ${ }^{15}$ Corroborando a esta questão, em estudo realizado por Barcelos, Porto e Geller, ${ }^{18}$ comprovou-se que $90 \%$ do grupo entrevistado acredita na facilitação da comunicação através da aprendizagem da LIBRAS por parte do professor, ressaltando também a importância da utilização de vários outros estímulos de comunicação visual, auxiliando no processo de ensino do aluno.

Deve-se deslocar a atenção do surdo para elementos chaves da tarefa, através de dicas e informações curtas, sucintas e objetivas, administradas uma de cada vez, o que não irá sobrecarregar o indivíduo de conhecimento e atividades a serem realizadas. ${ }^{15}$ Podemos perceber este fato em qualquer âmbito da Educação Física e, diria até, do conhecimento em geral, já que em primeiro lugar é necessária uma introdução sobre o assunto a ser abordado para depois, os itens serem tratados minuciosamente, até ser atingido o objetivo final.

Gonçalves, Vaz e Fernandes ${ }^{17}$ realizaram uma investigação em que o conteúdo LIBRAS foi apresentado durante a aula, aos alunos, com o propósito de que os mesmos conhecessem outras possibilidades de comunicação, não somente a linguagem oral. Nesse sentido, de acordo Venditti Júnior e Araújo, ${ }^{16}$ em questões de expressão corporal, influenciados pela expressividade apurada, os surdos têm muito para nos ensinar e, também, para ensinar aos colegas. É fundamental ressaltarmos a importância do conhecimento trazido pelo aluno para dentro da sala de aula, o que pode promover diversos novos caminhos de discussão. No caso, os surdos poderiam contribuir positivamente na aquisição e aprimoramento da expressividade dos alunos ouvintes, demonstrando, dando dicas, aumentando a qualidade e a quantidade de comunicação com seus colegas, independente da estratégia utilizada para este fim.

A dança, por exemplo, constitui-se em um meio de trabalho, uma estratégia de comunicação que utiliza da linguagem corporal, a qual pode promover a reflexão crítica, favorecendo a socialização e a construção de um indivíduo autônomo. ${ }^{11}$ De acordo com Luiz, ${ }^{13}$ o desenvolvimento dessa linguagem corporal permitirá a manifestação da personalidade do surdo e também de um conhecimento mais completo sobre si mesmo, permeando tanto a comunicação inter, quanto intrapessoal.
Percebe-se a grande importância da linguagem corporal para os surdos, pois durante o seu desenvolvimento, essa linguagem é utilizada fortemente como meio de comunicação, fazendo com que sua corporeidade seja reconhecida e lapidada. A dança pode ser utilizada como agente transformador em prol da melhoria da linguagem na comunicação, permitindo que o aluno saia de seu isolamento. ${ }^{12}$

De acordo com Alves, Santos e Carvalho, ${ }^{11}$ é muito comum que estes sujeitos acabem se retraindo, se afastando dos demais colegas e formando círculos de amizade com indivíduos em situação parecida com a sua, além da própria família. Este acontecimento acaba por diminuir a convivência com diferentes "tipos de pessoas" e as possibilidades de trocas de informações que isso poderia vir a ocasionar. Essa troca de conhecimento é indispensável para facilitar o aprendizado do aluno surdo e dos demais colegas. Caso contrário, o aluno começa a não participar das aulas de Educação Física, as quais poderiam proporcionar situações de convívio social, sempre mediadas pelo professor que, em tese, possui competência para fazê-lo de um modo adequado e participativo. Em contrapartida, a investigação realizada por Venditti Júnior e Araújo ${ }^{16}$ nos sugere que a diminuição no número de alunos, proporcionou uma maior aceitação e interação coletiva, devido ao fato de que a comunicação passou a ser mais valorizada e o círculo de relações, mais harmonizado.

Percebe-se que, quanto maior o auxílio do professor, mais rapidamente o aluno consegue evoluir e, esse fator pode ter sido o principal mediador da aceitação coletiva. Já, a questão da interação coletiva acabou se tornando mais fácil devido a menor diversidade de pessoas no grupo, ocasionando poucos pontos de vista diferentes, menos discussões, mais conhecimento um do outro, de seus objetivos e metas, enfim.

É necessário observar que a comunicação influencia diretamente nas relações entre o surdo e as pessoas que estão inseridas em seu contexto diário. Percebe-se que uma comunicação adequada desde muito cedo, pode fazer com que a criança se sinta preparada e confiante para estabelecer relações, formar seu círculo de amizades e evoluir progressivamente em diversos aspectos. Além disso, é fundamental que o professor tenha condições de dialogar com este aluno, caso contrário seu desenvolvimento pode ser afetado negativamente. É normal que o surdo tenha dúvidas durante a explicação das atividades, principalmente porque os professores não dominam a LIBRAS, a linguagem mais utilizada e compreendida por este público. Apesar disto, outros recursos podem ser utilizados, como imagens, figuras e demonstrações dos exercícios a serem realizados, bem como o auxílio cinestésico pode ser executado para facilitar o feedback para a pessoa surda.

\section{CONSIDERACִÕES FINAIS}

Por meio da leitura e análise dos artigos, publicações em anais de congressos, teses e dissertações, foi possível estabelecer uma conexão entre o surdo e a área da Educação Física. Esta conexão precisa ser entendida como uma forma de diálogo entre eles, o que estabelece a necessidade de uma comunicação adequada e 
eficiente, que possa fazer com que essa relação seja mais estreita. Pela diversidade dos assuntos tratados nas publicações, podemos perceber a variedade de focos de análise, sendo alguns pouco tratados de forma especifica.

Embora houvesse a diversidade dos assuntos abordados, poucos foram aprofundados em determinados pontos. Grande parte dos trabalhos encontrados aborda superficialmente uma questão fundamental para o trabalho com surdos, seus sentimentos e sensações, além das expectativas e objetivos a serem atingidos pelos mesmos. Com base nestas informações, poderiam ser estabelecidas múltiplas possibilidades de estudo, de acordo com o público alvo e, não só com a vontade ou necessidade do pesquisador.

Ao mesmo tempo, a comunicação entre o surdo e as pessoas com as quais ele se relaciona, ganha papel de destaque em quase todas as investigações encontradas, visto que a utilização de um intérprete se fez presente nas mesmas. A pessoa surda possui na LIBRAS uma forma de comunicação quase exclusiva, entretanto não rejeita outras, como foi observado em estudos. Todavia, elementos acabam não sendo tratados de forma adequada, como os componentes técnicos da dança, por exemplo, o que faz com que, apesar dos esforços, o surdo não tenha a mesma autonomia dos ouvintes frente algumas situações específicas, principalmente em relação ao ritmo que é externo a ele.

Entretanto, mesmo que diversos assuntos tenham sido abordados, foi evidenciada uma carência de publicações na área da Educação Física sobre o surdo. Percebe-se que a maioria dos trabalhos analisados foi publicada a partir dos anos 2000, revelando que a preocupação com este público alvo é recente. A necessidade de novos estudos se torna importante à medida que a diversidade aparece como tema recorrente na sociedade atual, na qual o surdo ocupa seu espaço com muita luta e perseverança.

\section{REFERÊNCIAS}

1. Nicolosi L, Harryman E, Kre J. Vocabulário dos distúrbios da comunicação: fala, linguagem e audição. Porto Alegre: Artes Médicas, 1996.

2. Enciclopédia Mirador Internacional. São Paulo: Enciclopédia Britânica do Brasil Publicações Ltda., 1987.

3. Barbosa MO. Bullying e surdez nas aulas de Educação Física escolar: o que pensam os atores envolvidos. In: XVII Congresso Brasileiro de Ciências do Esporte, Porto Alegre, 2011.

4. Nóbrega JD, Andrade AB, Pontes RJS, Bosi MLM, Machado MMT. Identidade surda e intervenções em saúde na perspectiva de uma comunidade usuária de língua de sinais. Ciência \& Saúde Coletiva (Rio de Janeiro) 2012; 17(3): 671-679. DOI: http://dx.doi.org/10.1590/S141381232012000300013.
5. Klein M, Lunardi ML. Surdez: um território de fronteiras. Educação Temática Digital, (Campinas) 2006; 7(2): 14-23.

6. De Paula LSB. Cultura escolar, cultura surda e construção de identidades na escola. Revista Brasileira de Educação Especial (Marília) 2009; 15(3): 407-416.

7. Diniz D. Autonomia reprodutiva: um estudo de caso sobre a surdez. Caderno de Saúde Pública (Rio de Janeiro) 2003; 19(1): 175-181.

8. Skliar C. Discursos y práticas sobre a deficiência y normalidad. Lãs exclusiones del lenguaje, del grupou de la mente. In: Gentili P. Códigos para la ciudadania. La formación ética como prática de la libertad. Madrid/Buenos Aires: Santillana, 2000.

9. Gesueli ZM. Lingua(gem) e identidade: a surdez em questão. Educação \& Sociedade (Campinas) 2006; 27(94): 277-292.

10. Marconi MA, Lakatos EM. Fundamentos de metodologia científica. In: Fundamentos de metodologia científica. São Paulo: Atlas, 2010.

11. Alves KP, Santos LF, Carvalho S. A importância da dança para o reconhecimento dos surdos sobre a sua corporeidade: um relato de experiência. In: IV Congresso Centro-Oeste de Ciências do Esporte, Brasília, 2010.

12. Lopes KF, Araújo PF. Proposta de ensino de sapateado para crianças surdas. Revista Brasileira de Ciência e Movimento (Campinas) 2009; 17(1): 1-22.

13. Luiz TRB. Avaliação de um programa de atividades rítmicas adaptada à pessoas surdas para variação dos parâmetros de velocidade no ritmo. Dissertação (Mestrado em Educação Física) - Universidade Estadual de Campinas, Campinas, 2001.

14. Rossi TRF. Brincar: uma opção para a interação entre mãe ouvinte/filho surdo. Tese (Doutorado em Educação Física) Universidade Estadual de Campinas, Campinas, 2000.

15. Pasetto SC. Os efeitos da utilização de dicas visuais no processo ensino-aprendizagem de habilidades motoras de aprendizes surdos. Dissertação (Mestrado em Educação Física) - Universidade Estadual de Campinas, Campinas, 2004.

16. Venditti Júnior $R$, Araújo PF. Trilhas ecológicas com orientação para pessoas surdas. Pensar a Prática (Goiânia) 2008; 11(3): 269-280.

17. Gonçalves GC, Vaz AF, Fernandes LZ. Itinerários da inclusão de pessoas com histórico de deficiência: um estudo sobre uma menina surda em aulas regulares de Educação Física. Movimento (Porto Alegre) 2002; 8(3): 63-71.

18. Barcelos RA, Porto A, Geller, CA. O ensino dos esportes para sujeitos com surdez. In: Congresso Sudeste de Ciências do Esporte, Niterói, 2010.

19. Pedrosa VS, Beltrame ALM, Boato EM, Sampaio TMV. A experiência dos professores de Educação Física no processo de inclusão escolar do estudante surdo. Revista Brasileira de Ciências do Movimento (Brasília) 2013; 21(2): 106-115.

20. Nazareth VL. Proposta de ensino básico da esgrima para adolescentes surdos. Dissertação (Mestrado em Educação Física) - Universidade Estadual de Campinas, Campinas, 2001. 